Europe's Journal of Psychology, 7(2), pp. 337-358

www.ejop.org

\title{
Evaluating Sorensen's Therapy for Instability in Mood (STIM) in the case of bipolar disorder
}

\author{
Maria J. Gutierrez \\ South Essex Partnership NHS Trust \\ John Sorensen \\ North Staff. Comb. Healthcare NHS Trust \\ Emily Tomlinson \\ Newham Psychological Therapy Service
}

\begin{abstract}
This study's aims were to evaluate the effects of Sorensen's Therapy of Instability in Mood (Sorensen, 2005; Sorensen, Done \& Rhodes, 2007), an intervention based on a short relapse-prevention program for clients suffering from Bipolar Disorder (BD), delivered within a clinical setting, by an assistant psychologist with limited training in CBT. The experimental treatment consisted of four individual sessions in addition to treatment as usual. Twelve clients with diagnoses of BD participated. Outcomes were measured across four domains: symptom severity, perceived hopelessness, perceived control over symptoms and level of insight. Measures of client satisfaction were also collected. Statistical analysis of the data revealed significant improvements to depression and perceived control levels at both one and three month follow-ups. In addition, clients reported significantly lower levels of hopelessness at three months follow-up. The study also considered the clinical significance of the research findings with the Jacobson-Truax (Jacobson \& Truax, 1991) method. A substantial number of clients attained clinically significant changes with regards to depression, hopelessness and perceived control at one and three months follow-ups. Recovery rates at three months were $50 \%, 41.6 \%$ and $25 \%$ respectively. Neither statistically nor clinically significant changes were found with regards to mania or insight at either one or three month follow-ups. All clients reported high levels of satisfaction.
\end{abstract}

Keywords: Cognitive-behavioural therapy, psycho-education, brief intervention relapse prevention, bipolar disorder, clinical significance analysis and single case design. 
Introduction

Bipolar disorder (BD) is a recurrent condition characterised by extreme changes in mood and is associated with significant morbidity and mortality. Annual prevalence rates in the year 2004 have been reported to be between 1.3\% and $2 \%$ in the UK (Regeer et al., 2004). Subsyndromal symptoms, mainly depression and significant psychosocial deficits such as poor work adjustment are often reported (Post et al., 2003). BD seldom occurs in the absence of other mental health problems and has been associated (more than any other psychiatric disorder) with heightened suicidality (Miklowitz \& Johnson, 2006; Newman, 2005): One in four people diagnosed with BD attempt suicide (Dalton, Cate-Carter, Mundo, Parikn \& Kennedy, 2003). Indeed suicidal ideation is frequent and around 15\% of BD patients commit suicide (Mclntyre et al., 2008).

The burden of suffering is not restricted to the patient, but also impacts on the family. Almost $60 \%$ of BD sufferers divorce or separate and most clients tend to have significant long term disability and impaired occupational and social functioning (Michalak, Yatham \& Lam, 2005; Michalak, Yatham, Maxwell, Hale \& Lam, 2007; Simon, Ludman, Unutzer, Operskalski \& Baver, 2008). The economic costs resulting from BD are considerable and estimated to have cost the UK £2 billion in 2001 (Das Gupta \& Guest, 2002).

The main treatment modality has been pharmacotherapy; however, despite its efficacy in treating the acute phase of the illness, many patients experience multiple relapses. Further, the positive results obtained in clinical trials of medication have not been replicated in clinical practice and the medical approach working in isolation has significant limitations at both symptomatic and functional levels, as illustrated by the lack of long-term effectiveness and non-adherence (Greenhouse, Meyer \& Johnson, 2000; Huxley, 2002; Keck, McElroy, Strakowski, Bourne \& West, 1997; Kessler et al., 1997; Nilson, 1999). In a longitudinal study Gitlin, Swendsen, Heller and Hammen (1995) found a relapse risk of $37 \%$ after one year and $73 \%$ after five or more years for patients on continual mood-stabilizing medication.

Medical intervention alone therefore has been unable to meet the wider needs of patients with BD and as a result, an increased interest in the benefits of adjunctive psychosocial approaches emerged. Cognitive Behavioural Therapy (CBT), Psychoeducational Interventions (PE), Family Therapy and Interpersonal and Social Rhythm Therapy (IPSRT) have been found to be valuable when combined with pharmacotherapy in the treatment of BD in randomised control trials (RCTs) (Colom, 
Vieta, Martinez-Aran et al., 2003; Lam et al., 2000; Lam et al., 2003; Scott, Garland \& Morhead, 2001). Evidence suggests that, at least for a subgroup of clients, better outcomes are achieved when psychosocial interventions are added to pharmacotherapy (lbid). However, the clinical reality for most users of the National Health Service is that despite all the years of research, the treatment for this illness is, still predominantly pharmacological.

Several reasons can be considered to account for this. For a start, the resources available in research are different from those in the mental health service and the benefits observed in the 'laboratory' setting are often not transmitted to real life clinical practice. Except for a few psychosocial interventions (Cochran, 1984; Perry, Tarrier, Morris, McCarthy \& Limb, 1999) the majority of approaches are delivered by highly skilled clinicians with many years of experience (Lam et al., 2003; Miklowitz et al., 2000; Scott et al., 2006) and even where manuals are available detailing the steps of an intervention, this tends to be insufficient. The complexity of the approach normally requires the provision of supervision and training, usually delivered through training centres to ensure that the clinician becomes a competent practitioner in the delivery of a particular approach. Many approaches are delivered over long periods of time, often between 20 and 30 sessions over a minimum of six months (Lam, Jones, Hayward \& Bright, 1999; Miklowitz et al., 2000). Providing these long term interventions within Community Mental Health Teams and Psychology services is a challenge when considering that most already struggle with long waiting lists and limited staff resources.

The reality is that most people with $\mathrm{BD}$ do not receive any form of therapy for the reasons stated above and those who have in the past, are often participants in research programs and only do so after many years of having received a diagnosis of $B D$. There is no doubt, that psychological interventions for BD need to be effective, but to be applicable to clinical practice they also need to match the resources available in today's health care system. Some authors advocate the use of brief interventions that can be delivered by less skilled or less experienced professionals in shorter periods of time and indeed the value of shorter interventions (4 to 12 sessions) has been shown in some RCTs. Cochran (1984) was among the first to demonstrate that 6 sessions of a CBT programme whose main aim was to increase compliance with medication was a very cost effective intervention. Later Perry and colleagues (1999) also promoted a short intervention based exclusively on relapse prevention. More recently, Sorensen developed an intervention based on a short relapseprevention program named The Sorensen Therapy for Instability in Mood (STIM) (Sorensen, 2005; Sorensen, Done \& Rhodes, 2007). A major advantage of this brief 
intervention is that it is designed to be delivered by staff with very little training in CBT. These are important factors that make this intervention easily applied and delivered to clients with BD, and therefore of special interest for pressured and often under resourced NHS Psychology Services.

There has been only one study (Sorensen et al. 2007), which evaluated the feasibility of this program with 13 BD clients. The results were positive and promising, however the intervention was delivered by an experienced psychologist, and therefore the claim that it can be administered by less experienced clinicians has yet to be confirmed. The study reported here aimed to evaluate the effects and acceptability of STIM (Sorensen, 2005) when it is delivered as an adjunct to pharmacotherapy to patients suffering from BD by staff with limited training in CBT (such as Assistant Psychologists) and within a clinical setting.

The Sorensen Therapy for Instability in Mood (STIM)

STIM consists of four individual sessions of a relapse prevention programme, delivered in most cases over four consecutive weeks by an Assistant Psychologist. Sessions last for 50 minutes. Session one helps the client develop a better understanding of BD in general terms and in relation to their personal experience of it. The stress-vulnerability framework, developed by Zubin and Spring (1977) is described in order to differentiate between what may cause an initial episode of BD and factors which influence the likelihood of future relapse into an illness episode. The aims of sessions two and three are to increase the client's awareness of early signs, symptoms and triggers for both depressive and manic episodes and the identification of an individual symptom profile as well as discussing coping strategies. In session four, the illness management strategies agreed in previous sessions are integrated and applied to the client's work and social related activities. Each client is given a handbook to complete during the therapy sessions summarising the main aspects of the therapy and is encouraged to continue using them after termination of the therapy.

Method

Inclusion/exclusion criteria

Clients were included in the study if they were aged 18 years or older, fulfilled diagnosis of BD I or BD II according to the Diagnostic and Statistical Manual of Mental Disorders (DSM-IV) (APA, 2000) or the International Statistical Classification of 
Diseases and Related Health Problems (ICD-10)(WHO,1990), were able to give informed consent and were fluent in English. Clients were excluded if they had a primary substance abuse disorder, were suffering from an organic brain syndrome or were receiving psychological treatment. Clients were also excluded if they were considered to be in an acute state for mania, hypomania or mixed state as defined by Bech-Rafaelsen Mania Scale $\geq 15$ (Bech, Rafaelsen, Kramp \& Bolwig, 1978) and The Beck Depression Inventory second edition $\geq 50$ (Beck, Steer, \& Brown, 1996). The criteria for exclusion of clients in an acute state for mania was similar to that used in other research studies, where the effectiveness of psychosocial interventions was evaluated (Lam et al., 2000; Lam et al., 2003; Lam, Hayward, Watkins, Wright \& Sham, 2005), but the criteria for acute depression differed from that employed in previous research $(\mathrm{BDI}>29)$. It was decided that the commonly used cut off for depression (BDI> 29) was too low (ibid) and that if applied it would exclude a considerable proportion of clients with $\mathrm{BD}$ living in the community, who were reasonably stable. It was also felt that there is a need for treatments for BD clients presenting with significant subsyndromal symptoms and this had not been addressed by previous research. The final sample consisted of 12 clients. Except for one client (8.3\%), the entire sample were taking medication $(91.6 \%, \mathrm{~N}=11)$. Of those on medication, $83.3 \%(\mathrm{~N}=10)$ were on mood stabilising medication, $75 \%(\mathrm{~N}=9)$ on antidepressants and $50 \%(\mathrm{~N}=6)$ received both. Their medication was not changed during the treatment intervention phase, but the study did not have the resources to control for changes in medication during the follow up phase. Equally, no measures were taken of the amount of professional contact that clients may have received from their local mental health team during the study.

\section{Outcome measures}

The variables expected to be influenced by the intervention included symptoms of mania and depression; level of hopelessness; level of insight and degree of control over internal states. A measure of the level of satisfaction with the intervention was also employed.

On entering the study participants completed a 45-minute semi-structured interview, which included information about their demographic characteristics, current and past psychiatric history and current treatments. Measures were collected by ET and MJG and were compiled during the pre-treatment baseline period, three times over five weeks and an average score was then computed. The same measures were repeated at the end of session 1, mid treatment (after session 2), at the end of treatment (after session 4) and at one and three months follow-up. 
The following measures were employed: the Beck Depression Inventory Second Edition (BDI-II) (Beck, et al., 1996), the Bech-Rafaelsen Mania Scale (BRMRS) (Bech et al., 1978), the Beck Hopelessness Scale (BHS) (Beck, Weissman, Lester \& Trexler, 1974), the Insight Scale (Birchwood, Smith, Drury, \& Healy, 1994), the Perceived Control Over Internal States (Pallant, 2000) and the Client Satisfaction Questionnaire (CSQ-8) (Larsen, Attkisson, Hargreaves \& Nguyen, 1979). All the outcome measures above, are well validated and widely used in the research literature, where CBT interventions, for the management of BD have been employed (Scott et al., 2001; Lam et al., 2005; Sorensen et al., 2007).

Intervention

In addition to treatment as usual (TAU), clients in the study received an active intervention based on relapse-prevention (STIM) (Sorensen, 2005). TAU included any medication that the psychiatrist treating an individual client considered appropriate, dosages being adjusted as necessary. As part of the standard treatment individuals could receive support from members of the multidisciplinary community team such as nurses, social workers or support workers. No other form of psychological therapy was considered during the study period.

The intervention was delivered by an Assistant Psychologist (ET), who received weekly supervision. She had a BSc (Hons) in Psychology and had completed a 20 week course in basic counselling skills. As an undergraduate she gained experience as a health care assistant/senior support worker with various client groups in disparate settings working for the NHS, private health care organisations and charities. The AP received around eight hours of training from MJG on the relapse prevention model proposed by Sorensen and the rationale for it. Treatment integrity was ensured with the use of audio tapes and supervision. Clients were asked to give their consent to the audio tape of one session, chosen prior to the therapy commencing, Audio tapes were then analysed by the first author with the use of a rating scale specifically designed to measure whether the components of the session being evaluated had been implemented as expected.

Data Analysis

A statistical analysis of the mean differences between pre treatment and one month follow up and pre-treatment and three months follow up was performed with the paired-samples t-test, provided that the assumption of normality was met or with its non-parametric equivalent, the Wilcoxon signed-rank test where it was not. 
Many researchers have advocated adding 'clinical significance' as a criterion for evaluating psychotherapy (Kazdin, 1982; Kendall, 1984; Wolf, 1978). However the majority of published studies rely exclusively on group means and statistical significance tests in evaluating treatment effects. There are two limitations with relying exclusively on group means. Firstly, it ignores individual variability (Barlow, 1981; Garfield, 1981; Hugdahl \& Ost, 1981) and for clinician's in routine practice, there is an interest in determining how each individual has responded to the treatment. Secondly, it has been accepted that changes can be statistically significant without being clinically meaningful (Kazdin \& Wilson, 1978).

Jacobsen and colleagues developed, over a number of years, a method for defining clinical significance in psychotherapy (Jacobson, Follette \& Revenstorf, 1984; Jacobson, Follette \& Revenstorf, 1986; Jacobson \& Revenstorf, 1988; Jacobson \& Truax, 1991). The method which is generally referred to as the Jacobsen-Traux (JT) method established a two-fold criteria. First they proposed the use of a Reliable Change Index (RC) to determine if a change is reliable and not due to measurement error. This RC can be calculated with the formulae below. If the RC obtained for each client is greater or lesser than + / - 1.96 (depending on whether the instruments are positive or negative) then one can conclude with a $95 \%$ probability $(p<.05)$ that the change is reliable and not the result of an unreliable measuring instrument.

$$
\begin{array}{ll}
R C=\frac{x_{2-} x_{1}}{S_{\text {diff }}} & x_{1}=\text { Client's pre-test score } \\
x_{2}=\text { Client's post-test score } \\
S_{\text {diff }}=\sqrt{2\left(S_{E}\right)^{2}} & \begin{array}{l}
S_{\text {diff }}=\text { Standard error of difference between two tests } \\
S_{E}=s_{1} \sqrt{1-r x x}
\end{array} \\
S_{1}=\quad \text { SD of the normal (functional) population } \\
r x x=\text { Internal consistency of the measure }
\end{array}
$$

Secondly, the client's score at post-treatment has to fall within the normal population range, rather than within the dysfunctional population range for a clinical significant change to occur. JT suggested using either cut-off ' $a$ ', 'b' or ' $c$ ' to separate the functional from the dysfunctional populations. JT recommends using criterion ' $c$ ' if norms for both the functional and dysfunctional populations are available. If norms are not available criterion ' $a$ ' and ' $b$ ' has to be used instead. A detailed explanation of these three cut-off points and the equations used to calculate them is provided below. 
Criterion a: Clinically significant change is achieved when the client's level of functioning at post-test falls outside the range of the dysfunctional population. The range is defined 'as extending two standard deviations beyond (in the direction of functionality) the mean of the dysfunctional population' (Jacobson et al., 1984, p. 340).

$$
\begin{array}{ll}
a=M_{1}+2 s_{1} \quad & M_{1}=\text { Mean dysfunctional } \\
s_{1}= & \text { SD dysfunctional }
\end{array}
$$

This equation applies to positive instruments (higher scores indicative of functionality) when dealing with negative instruments (higher scores indicative of dysfunctional) the equation should be converted to:

$$
a=M_{1}-2 s_{1}
$$

Criterion b: Based on this criterion clinically significant change is achieved when the client's level of functioning at post-test falls within the range of the functional population, 'where range is defined as extending two standard deviations below the mean of the normal population' (Jacobson et al., 1984, p. 340).

$$
\begin{array}{ll}
b=M_{0}-2 s_{0} & M_{0}=\text { Mean functional } \\
s_{0}=\text { SD functional }
\end{array}
$$

This equation applies to positive instruments, when dealing with negative instruments the equation should be converted to:

$$
b=M_{0}+2 s_{0}
$$

Criterion c: This criterion applies when the client's post-test score is more likely to have been drawn from the functional population rather than the dysfunctional group.

$$
\begin{aligned}
& c=\frac{s_{0} M_{1}+s_{1} M_{0}}{s_{0}+s_{1}} \\
& M_{0}+s_{0}=\text { Mean and SD of the functional population } \\
& M_{1}+s_{1}=\text { Mean and SD of the dysfunctional population }
\end{aligned}
$$

Criterion ' $a$ ' is the most stringent criterion, criterion $b$ is more lenient and criterion ' $c$ ' falls in between. A visual representation of these three cut-off points has been presented in Figure 1 below. 
Functional Dysfunctional

population population

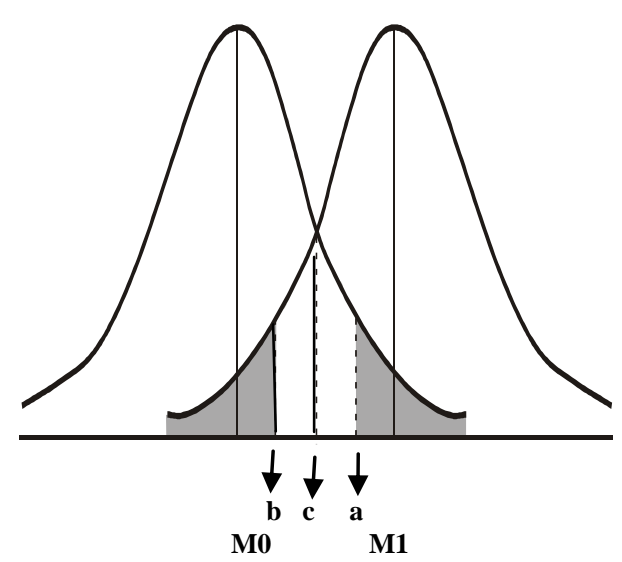

$M_{0}=$ Mean dysfunctional population

$M_{1}=$ Mean functional population

Figure 1. Visual Representation of Jacobson-Truax (JT) Cut-off Points for a hypothetical subject.

The JT method allows for further classifying clients into categorical ratings for clinical improvement into Recovered, Improved, Unchanged or Deteriorated according to whether or not the client has met the above criteria. The clinical significance of the change experience by each client was analysed only for the measures where a statistically significant effect has been found. The data used in the calculations is provided in Table 1.

Table 1. Data used to determine the RCI(s) and cut off points for the BDI-II, BHS and PCOISS.

\begin{tabular}{|llll|}
\hline & BDI-II & BHS & PCOISS \\
\hline Rxx & 0.93 (Beck et al., 1996) & 0.92 (Beck \& Steer, 1988) & 0.90 (Pallant, 2000) \\
SD & 7.57 (Dozois et al., 1998) & 3.09 (Greene, 1981) & 12 (Pallant, 2000) \\
$M_{0}$ & 9.11 (Dozois et al., 1998) & 4.45 (Greene, 1981) & 60.6 (Pallant, 2000) \\
$s_{0}$ & 7.57 (Dozois et al., 1998) & 3.09 (Greene, 1981) & 12 (Pallant, 2000) \\
$M_{1}$ & 22.45 (Beck et al., 1996) & 9.98 (Beck et al., 1990) & \\
& & & \\
$S_{1}$ & 12.75 (Beck et al., 1996) & 5.42 (Beck et al., 1990) & \\
\hline
\end{tabular}




\section{Results}

A one way repeated-measures ANOVA was conducted to compare scores on the BDI-II, BMRS, BHS, Insight Scale and PCOISS across the three baselines points (B1, B2 and B3) to investigate the stability of the measure prior to the intervention. For all outcome measures there was a non significant effect across time, which led to conclude that the assumption of independence of observation and stability of the behaviour has been met. The results have been illustrated in the Table 2 below.

Table 2. Results of analysis across all baseline measures for all outcome measures.

\begin{tabular}{|llll|}
\hline & & & \\
Outcome measures & Wilks' Lambda & $F$ & Sig \\
BDI-II & 0.743 & $F(2,10)=1.727$ & 0.227 \\
BMRS & 0.875 & $F(2,10)=0.712$ & 0.514 \\
BHS & 0.872 & $F(2,10)=0.737$ & 0.503 \\
Insight Scale & 0.823 & $F(2,10)=1.075$ & 0.378 \\
PCOISS & 0.924 & $F(2,10)=0.413$ & 0.673 \\
\hline
\end{tabular}

Analysis of statistical significance

Statistically significant results were found for depression and perceived control over internal states scores between baseline and one month follow up and also between baseline and three months follow-up. For hopelessness scores significant differences with large effect sizes were found between baseline and three months follow-up, but not between baseline and one month follow up. For mania and for level of insight scores no significant differences were obtained at any stage. Table 3 and Table 4 below present the results of this analysis.

Table 3. Results of statistical analysis between baseline and 1 month follow-up.

\begin{tabular}{|c|c|c|c|c|c|c|c|c|}
\hline \multirow{2}{*}{$\begin{array}{l}\text { Outcome } \\
\text { Measures }\end{array}$} & \multicolumn{2}{|c|}{ Baseline } & \multirow[b]{2}{*}{ Median } & \multicolumn{2}{|c|}{1 month FU } & \multirow[b]{2}{*}{ Median } & \multirow[t]{2}{*}{$t / z$} & \multirow[t]{2}{*}{ Sig (2-tailed) } \\
\hline & Mean & (SD) & & Mean & (SD) & & & \\
\hline BDI-II & 21.86 & (12.83) & 19.83 & 12.92 & (14.03) & 9.00 & $z=-2.492$ & $0.013^{*}$ \\
\hline BMRS & 4.25 & $(2.76)$ & 3.5 & 4.67 & $(2.77)$ & 4.50 & $t=-0.535$ & 0.603 \\
\hline BHS & 9.5 & $(5.61)$ & 9.83 & 6.83 & $(6.96)$ & 4 & $t=1.580$ & 0.143 \\
\hline Insight & 10.06 & (1.54) & 10.33 & 10.08 & $(2.06)$ & 10.50 & $z=-0.178$ & 0.858 \\
\hline PCOISS & 41.22 & $(12.40)$ & 40.66 & 59.75 & (15.63) & 58 & $\dagger=-4.44$ & $0.001 *$ \\
\hline
\end{tabular}


Table 4. Results of statistical analysis between baseline and 3 months follow-up.

\begin{tabular}{|c|c|c|c|c|c|c|c|c|}
\hline \multirow{2}{*}{$\begin{array}{l}\text { Outcome } \\
\text { Measures }\end{array}$} & \multicolumn{3}{|c|}{ Baseline } & \multicolumn{3}{|c|}{3 month FU } & \multirow[t]{2}{*}{$t / z$} & \multirow[t]{2}{*}{ Sig (2-tailed) } \\
\hline & Mean & (SD) & Median & Mean & (SD) & Median & & \\
\hline BDI-II & 21.86 & (12.83) & 19.83 & 10.42 & (7.24) & 10.00 & $t=2.7 .82$ & $0.018^{*}$ \\
\hline BMRS & 4.25 & $(2.76)$ & 3.5 & 3.92 & (3.47) & 3.0 & $t=0.263$ & 0.797 \\
\hline BHS & 9.5 & $(5.61)$ & 9.83 & 5.08 & (5.31) & 2.50 & $t=2.708$ & $0.020 *$ \\
\hline Insight & 10.06 & (1.54) & 10.33 & 10.33 & (1.77) & 10.50 & $z=-1.024$ & 0.306 \\
\hline PCOISS & 41.22 & (12.40) & 40.66 & 59.25 & (14.91) & 60 & $t=-3.66$ & $0.004^{*}$ \\
\hline
\end{tabular}

\section{Reliable Change}

As stated above the Reliable Change Index (RC) was calculated for the BDI-II, BHS and PCOISS. A summary is presented in Table 5 below with clients' scores on the BDI-II, BHS and PCOISS having to show a minimum change of 5.53, 2.41 and 10.50 points respectively in order to demonstrate either reliable improvement or reliable deterioration depending in what direction the change is.

The percentages and frequencies of clients achieving reliable change are shown in Table 5. It should be noted that not all the individuals achieving significant change at end of therapy or maintained their gains at one and three months follow-up. In order to identify what change each client experienced at each stage, subjects were allocated a number from 1 to 12, shown in brackets in Table 5. For instance, with regards to subject number 5's BDI-II scores, he did not achieve a significant change at the end of therapy, changed significantly between pre treatment and one month follow up, but did not maintain the gains at three months follow-up.

Table 5. Percentages and frequencies of clients achieving a reliable change on the BDI-II, BHS and PCOISS across all data collection points (The numbers in brackets identify the participants).

\begin{tabular}{|c|c|c|c|c|c|c|c|}
\hline & \multirow[t]{2}{*}{ Reliable Change (RC) } & \multicolumn{2}{|l|}{ End Therapy } & \multicolumn{2}{|l|}{1 Month FU } & \multicolumn{2}{|l|}{3 Month FU } \\
\hline & & n (participants) & $\%$ & n (participants) & $\%$ & n (particpants) & $\%$ \\
\hline \multirow[t]{4}{*}{ BDI-II } & $\begin{array}{l}\text { Significant Change } \\
\text { desired direction }\end{array}$ & $7(1,2,6,7,9,10,11)$ & 58.3 & $7(1,2,5,6,9,10,11)$ & 58.3 & $8(1,2,4,6,7,9,10,11)$ & 66.7 \\
\hline & $\begin{array}{l}\text { Significant Change } \\
\text { opposite direction }\end{array}$ & 0 & 0 & 0 & 0 & $1(8)$ & 8.3 \\
\hline & & & 41.7 & & & & \\
\hline & Not Significant Change & $5(3,4,5,8,12)$ & & $5(3,4,7,8,12)$ & 41.7 & $3(3,5,12))$ & 25 \\
\hline BHS & $\begin{array}{l}\text { Significant Change } \\
\text { desired direction: }\end{array}$ & $7(1,2,5,6,7,10,11)$ & 58.3 & $5(1,5,6,10,11)$ & 41.7 & $7(1,4,5,6,9,10,11)$ & 58.3 \\
\hline
\end{tabular}




\begin{tabular}{|clllllll|}
\hline \multicolumn{1}{c}{$\begin{array}{l}\text { Significant Change } \\
\text { opposite direction }\end{array}$} & $1(9)$ & 8.3 & $3(2,4,7)$ & 25 & $1(8)$ & 8.3 \\
& Not Sig. Change & $4(3,4,8,12)$ & 33.3 & $4(3,8,9,12)$ & 33.3 & $4(2,3,7,12)$ & 33.3 \\
PCOISS & $\begin{array}{l}\text { Significant Change } \\
\text { desired direction: }\end{array}$ & $6(1,2,5,9,10,11)$ & 50 & $7(1,2,5,9,10,11,12)$ & 58.3 & $8(1,2,5,6,7,9,10,11)$ & 66.7 \\
& $\begin{array}{l}\text { Significant Change } \\
\text { opposite direction }\end{array}$ & 0 & 0 & 0 & 0 & 0 & 0 \\
Not Sig. Change & $6(3,4,6,7,8,12)$ & 50 & $5(3,4,6,7,8)$ & 41.7 & $4(3,4,8,12)$ & 33.3 \\
\hline
\end{tabular}

Return to normal levels of functioning

The second condition of the JT method stipulates that a reliable change will be considered clinically significant only if the client's score at post-test (either at the end of therapy, one or three months follow-up) falls within the normal population range rather than in the dysfunctional population range. Given the availability of norms for both the functional and dysfunctional populations for the BDI-Il and the BHS scale, criterion ' $c$ ' has been employed. For the PCOISS only norms for the functional population were available, and therefore cut off ' $b$ ' was used. Clients' scores at post-treatment would have to fall below 14.07 for the BDI-II, below 3.28 for the BHS and above 36.6 for the PCOISS for the change to be considered clinically significant. The distributions of scores for the relevant outcome measures for both functional and dysfunctional populations are summarised in Table 6.

Table 6. Functional and dysfunctional populations according to the cut-offs for BDI-II, BHS and PCOISS.

Range scores JT cut-off Functional range Dysfunctional range

\begin{tabular}{|c|c|c|c|c|}
\hline BDI-II & $0-63$ & 14.07 & $0-14.07$ & $>14.07$ \\
\hline BHS & $0-20$ & 3.28 & $0-3.28$ & $>3.28$ \\
\hline PCOISS & $0-90$ & 36.6 & $36.6-90$ & $<36.6$ \\
\hline
\end{tabular}

The number of clients returning to normal levels of functioning, regardless of whether or not the change experienced was reliable, is presented in Table 7 below. There are some instances when this criteria is not applicable, which happens when the client's score at baseline was already within the functional range. This means that no matter how much their scores change in the desirable direction, their change can never be clinically significant according to the JT method. This is one of the limitations of this 
method. One way of addressing this would have been to ensure that at baseline all clients' scores were within the dysfunctional range. This would, however, have the disadvantage of excluding clients for treatment, who are dysfunctional in one of the other key areas of interest.

Table 7. Percentage and frequencies of clients showing a return to normative levels of functioning on the BDI-II, BHS and PCOISS across all data collection points.

\begin{tabular}{|c|c|c|c|c|c|c|c|}
\hline & & End Therap & $\%$ & $\begin{array}{l}\text { Post test } 1 \text { Month FU } \\
\mathrm{n}\end{array}$ & $\%$ & $\begin{array}{l}\text { Post test } 3 \text { Month FU } \\
\mathrm{N}\end{array}$ & $\%$ \\
\hline \multirow[t]{3}{*}{ BDI-II } & Criteria Achieved & $5(1,2,6,10,11)$ & 41.6 & $5(1,2,6,10,11)$ & 41.6 & $6(1,2,6,9,10,11)$ & 50 \\
\hline & Criteria Not Achieved & $3(4,7,9)$ & 25 & $3(4,7,9)$ & 25 & $2(4,7)$ & 16.6 \\
\hline & Criteria Not Applicable & $4(3,5,8,12)$ & 33.3 & $4(3,5,8,12)$ & 33.3 & $4(3,5,8,12)$ & 33.3 \\
\hline \multirow[t]{3}{*}{ BHS } & Criteria Achieved & $5(2,5,6,10,11)$ & 41.7 & $5(1,5,6,8,10,12)$ & 41.7 & $6(1,2,5,6,10,11,12)$ & 50 \\
\hline & Criteria Not Achieved & $6(1,3,4,7,8,9)$ & 50 & $6(2,3,4,7,9,11)$ & 50 & $5(3,4,7,8,9)$ & 41.7 \\
\hline & Criteria Not Applicable & $1(12)$ & 8.33 & $1(12)$ & 8.33 & $1(12)$ & 8.33 \\
\hline \multirow[t]{3}{*}{ PCOISS } & Criteria Achieved & $2(9,11)$ & 16.6 & $3(7 ., 9,11)$ & 25 & $3(7,9,11)$ & 25 \\
\hline & Criteria Not Achieved & $2(4,7)$ & 16.6 & $1(4)$ & 8.33 & $1(4)$ & 8.33 \\
\hline & Criteria Not Applicable & $8(1,2,3,5,6,8,10,12)$ & 66.6 & $8(1,2,3,5,6,8,10,12)$ & 66.6 & $8(1,2,3,5,6,8,10,12)$ & 66.6 \\
\hline
\end{tabular}

Clinical significance change and categorical ratings

The results of JT's double fold criteria and the respective categorical rating for each individual at the end of therapy, one month follow-up and three months follow-up has been summarised in Table 8.

Table 8. Percentage and frequencies of JT's categorical ratings of clinical improvement across phases for the BDI-II, BHS, PCOISS across all data collection points.

\begin{tabular}{|c|c|c|c|c|c|c|c|c|c|}
\hline & \multirow[t]{2}{*}{ Therapy Stage } & \multirow{2}{*}{$\begin{array}{l}\text { Recovered } \\
\mathrm{n}\end{array}$} & \multirow[b]{2}{*}{$\%$} & \multicolumn{2}{|l|}{ Improved } & \multicolumn{2}{|l|}{ Unchanged } & \multicolumn{2}{|c|}{ Deteriorated } \\
\hline & & & & $\mathrm{n}$ & $\%$ & $\mathrm{n}$ & $\%$ & $\mathrm{n}$ & $\%$ \\
\hline BDI-II & End of Therapy & $\begin{array}{l}5 \\
(1,2,6,10,11)\end{array}$ & 41.6 & $\begin{array}{l}2 \\
(7,9)\end{array}$ & 16.6 & $\begin{array}{l}5 \\
(3,4,5,8,12)\end{array}$ & 41.6 & 0 & 0 \\
\hline & 1 Month FU & $\begin{array}{l}5 \\
(1,2,6,10,11)\end{array}$ & 41.6 & $\begin{array}{l}2 \\
(9,5)\end{array}$ & 16.6 & $\begin{array}{l}5 \\
(3,4,7,8,12)\end{array}$ & 41.6 & 0 & 0 \\
\hline & 3 Month FU & $\begin{array}{l}6 \\
(1,2,6,9,10,11)\end{array}$ & 50 & $\begin{array}{l}2 \\
(4,7)\end{array}$ & 16.6 & $\begin{array}{l}3 \\
(3,5,12)\end{array}$ & 25 & $\begin{array}{l}1 \\
(8)\end{array}$ & 8.33 \\
\hline
\end{tabular}




\begin{tabular}{|c|c|c|c|c|c|c|c|c|c|}
\hline BHS & End of Therapy & $\begin{array}{l}4 \\
(2,5,6,10)\end{array}$ & 33.3 & $\begin{array}{l}3 \\
(1,7,11)\end{array}$ & 25 & $\begin{array}{l}4 \\
(3,4,8,12)\end{array}$ & 33.3 & $\begin{array}{l}1 \\
\text { (9) }\end{array}$ & 8.33 \\
\hline & 1 Month FU & $\begin{array}{l}4 \\
(1,5,6,10)\end{array}$ & 33.3 & $\begin{array}{l}1 \\
\text { (11) }\end{array}$ & 8.3 & $\begin{array}{l}4 \\
(3,8,9,12)\end{array}$ & 33.3 & $\begin{array}{l}3 \\
(2,4,7)\end{array}$ & 25 \\
\hline & 3 Month FU & $\begin{array}{l}5 \\
(1,5,6,10,11)\end{array}$ & 41.7 & $\begin{array}{l}2 \\
(4,9)\end{array}$ & 16.6 & $\begin{array}{l}3 \\
(2,7,12)\end{array}$ & 25 & $\begin{array}{l}2 \\
(3,8)\end{array}$ & 16.6 \\
\hline PCOISS & End of Therapy & $\begin{array}{l}2 \\
(9,11)\end{array}$ & 16.6 & $\begin{array}{l}4 \\
(1,2,5,10)\end{array}$ & 33.3 & $\begin{array}{l}6 \\
(3,4,6,7,8,12)\end{array}$ & 50 & 0 & 0 \\
\hline & 1 Month FU & $\begin{array}{l}2 \\
(9,11)\end{array}$ & 16.6 & $\begin{array}{l}5 \\
(1,2,5,10,12)\end{array}$ & 41.6 & $\begin{array}{l}5 \\
(3,4,6,7,8)\end{array}$ & 41.6 & 0 & 0 \\
\hline & 3 Month FU & $\begin{array}{l}3 \\
(7,9,11)\end{array}$ & 25 & $\begin{array}{l}5 \\
(1,2,5,6,10)\end{array}$ & 41.6 & $\begin{array}{l}4 \\
(3,4,8,12)\end{array}$ & 33.3 & 0 & 0 \\
\hline
\end{tabular}

Summary of results

The effects of this intervention were measured on depression, mania, hopelessness, insight and perceived control of internal states. As indicated in Table 9 below, a statistically significant difference for depression and perceived control over internal states scores has been found between baseline and both one and three months follow up. With regards to the hopelessness scores, the difference between baseline and one month follow up was not significant, but this changed when comparing the hopelessness scores between baseline and three months follow up. No significant differences were found for mania or for level of insight.

Table 9. Results of statistical analysis

\begin{tabular}{|llllll|}
\hline & Depression & Mania & Hopelessness & Insight & Perceived Control \\
\hline $\begin{array}{l}\text { Baseline and } \\
1 \text { Month FU }\end{array}$ & $\begin{array}{l}\text { Significant } \\
\text { Large Effect }\end{array}$ & Not Significant & Not Significant & Not Significant & Significant \\
Baseline and & Significant & Not Significant & Significant & Not Significant & Significant \\
3 Month FU & Large Effect & & Large Effect & & Large Effect \\
\hline
\end{tabular}

The application of the JT method provides information regarding individual variability and allows individuals to be classified into categorical ratings for clinical improvement. Discussions regarding the change experienced by each client after treatment are outside the scope of this article. Table 10 provides a summary of the percentages of clients in each category. It should be noted that a considerable percentage of clients were found to be Recovered and Improved at one month follow up with regards to depression $(41.6 \%$ and $16.6 \%$ respectively), hopelessness (33.3\% and $8.3 \%$ ) and perceived control (16.6\% and $41.6 \%$ ) and these figures were maintained at three months follow up. These results are consistent with those obtained in the statistical analysis. Clients' scores for mania were unchanged and this 
confirms the lack of any statistical significance effects. The JT method was not applicable to the Insight scale.

Table10. Summary of the percentages of clients in each JT categorical rating for each outcome measure

\begin{tabular}{|c|c|c|c|c|c|c|c|c|c|c|c|c|c|c|c|c|}
\hline \multirow[t]{2}{*}{ FU } & \multicolumn{4}{|c|}{ BDI-II } & \multicolumn{4}{|c|}{ BMRS } & \multicolumn{4}{|l|}{ BHS } & \multicolumn{4}{|c|}{ PCOISS } \\
\hline & 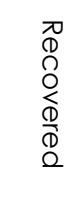 & $\begin{array}{l}\overline{3} \\
\overline{0} \\
\overline{0} \\
\mathbb{0} \\
\stackrel{0}{0}\end{array}$ & 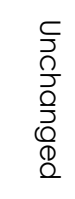 & 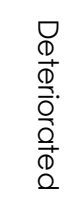 & $\begin{array}{l}\text { D } \\
\mathbb{D} \\
\stackrel{0}{0} \\
\stackrel{0}{0} \\
\stackrel{D}{D} \\
\stackrel{\Omega}{\Omega}\end{array}$ & $\begin{array}{l}\overline{3} \\
\overline{0} \\
0 \\
0 \\
0 \\
\stackrel{0}{\Omega}\end{array}$ & 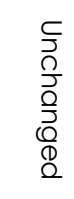 & 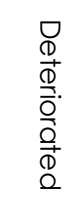 & 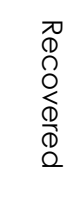 & $\begin{array}{l}\overline{3} \\
\overline{0} \\
\overline{0} \\
\Phi \\
0 \\
\alpha\end{array}$ & 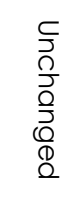 & 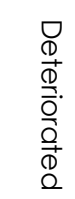 & 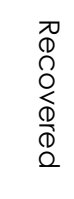 & $\begin{array}{l}\overline{3} \\
\frac{0}{0} \\
0 \\
\mathbb{0} \\
\stackrel{0}{0}\end{array}$ & 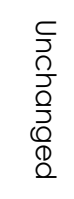 & 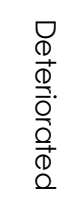 \\
\hline $1 \mathrm{M}$ & 41.6 & 16.6 & 41.6 & 0 & 0 & 0 & 100 & 0 & 33.3 & 8.3 & 33.3 & 25 & 16.6 & 41.6 & 41.6 & 0 \\
\hline $3 M$ & 50 & 16.6 & 25 & 8.3 & 0 & 0 & 100 & 0 & 41.6 & 16.6 & 25 & 16.6 & 25 & 41.6 & 33.3 & 0 \\
\hline
\end{tabular}

\section{Discussion}

This study adds to the weight of evidence that short psychological interventions based on CBT principles have beneficial effects for clients with BD. The results of both the statistical analysis and the application of the JT method indicated that a significant reduction in depressive symptoms and an increase in perceived control over internal states have been observed following the intervention between baseline and one month follow up and between baseline and three months follow-up. Significant differences in scores were also found between baseline and three months follow-up for hopelessness scores.

As expected, treatment effects were not consistent across measures for the sample as a group or with regards to each individual client. It appears that clients with mild levels of mania do not benefit from this intervention in terms of reducing their manic symptoms, despite every client receiving all the planned components of the intervention. This however is not an unusual finding; manic symptoms have shown not to respond to other similar interventions (Ball et al., 2006; Scott et al., 2001; Scott et al., 2006; Lam et al., 2005).

When clients were individually analysed, according to JT's methodology, a substantial proportion of clients were considered not only to have improved, but also to have recovered after the treatment intervention with regards to depression, perceived control over internal states and hopelessness. A major goal of this study was to ascertain the feasibility and acceptability of this intervention when applied by a non-expert therapist and the evidence suggests that this four week program for BD 
clients is not only feasible but acceptable. The acceptability of the program has been demonstrated by the very low drop-out rates, the high level of attendance at sessions (no clients drop-out after completing session 1) and the clients' compliance with the requirements of the intervention. Treatment acceptability was measured through the self-report satisfaction questionnaire (CSQ-8) that clients completed at the end of treatment; scores for all 12 clients fell within the 'High' satisfaction range (27-32). However, the interpretability of these results is questionable given that the anonymity was not ensured and the questionnaire was administered by the therapist delivering the intervention.

It is not possible to accord a causal role to the treatment intervention for these results, however, stability of the behaviour over five weeks at baseline, the immediacy of change following the intervention as well as the large magnitude of change observed, contribute to the argument that the treatment was responsible for the change. Unfortunately, the study did not control for changes in medication or frequency of psychiatric outpatient appointments. The main limitations of this study, which were partially dictated by practical issues relating to the research funding available and time constraints for completion of this project, were the lack of statistical power and that clinician delivering the intervention also participated in the scoring of instruments.

This is the second study aimed at examining the effects of STIM and the results are consistent with those from Sorensen and colleagues (2007) study in which 13 BD clients were offered the same intervention by a highly trained clinician. Outcomes were collected with regards to level of hopelessness, level of perceived control over internal states and satisfaction levels with the same instruments employed in this study. Depression, mania and insight were not measured and therefore cannot be compared. The follow-up period in the Sorensen and colleagues study was five weeks as opposed to one and three months in the present study. The only difference between these two studies refers to levels of hopelessness, both studies found a significant effect on BHS, but whereas Sorensen and colleagues (2007) observed a significant difference between baseline and one week post treatment and at five weeks follow up, this result was not replicated in this study. The present study found no significant differences at one month follow-up, but the differences between baseline and three months were statistically significant. Both studies identified a statistically significant difference for perceived control between baseline and each follow-up point (one and five weeks for Sorensen, one and three months for the current study). In considering what may account for the differences between these two studies, one should refer to the different levels of expertise of the clinician and to random variation in small samples. 
The main implication of this study is that the positive results obtained on depression, hopelessness and perceived control, coupled with the fact that this is a very short intervention requiring little training on the part of the clinician, together with the high levels of acceptability from clients, provide enough support for this type of treatment to be provided to a larger population. The present study should be replicated with larger samples and appropriate controls. It will be important to include longer follow up periods to determine whether or not the results are maintained over a longer course. In order to be able to compare this intervention to those more complex and widely researched, one needs to include a survival analysis. The primary measure against which the efficacy of an intervention in BD is measured is time to first relapse and whether the current reduction in symptoms, reduced levels of hopelessness and increase perceived control translate in lower relapse rates and longer time without relapse remains to be seen.

\section{References}

American Psychiatric Association (1996). Diagnostic and Statistical manual for Mood Disorders ( $4^{\text {th }}$ edn). Washington DC: American Psychiatric Association.

Ball, J.R., Mitchell, P.B., Corry, J., Skillecorn, A., Smith, M. \& Malh, G.S. (2006). A randomized controlled trial of cognitive therapy for bipolar disorder: Focus on long term change. Journal of Clinical Psychiatry, 67(2), 277-286.

Barlow, D.H. (1981). On the clinical research to clinical practice: Current issues, new directions. Journal of Consulting and Clinical Psychology, 49, 147-155.

Bech, P., Rafaelsen, O.J., Kramp \& Bolwig, T.G. (1978). The mania rating scale: scale construction and inter-observer agreement. Neuropharmacology, 17, 430-431.

Beck, A.T., Brown, G., Berchick, R.J., Stewart, B.L. \& Steer, R.A. (1990) Relationship between hopelessness and ultimate suicide: A replication with psychiatric outpatients. The American Journal of Psychiatry, 147(2), 190-195.

Beck, A.T. \& Steer, R.A. (1988). Manual for the Beck Hopelessness Scale. San Antonio, TX: The Psychological Corporation.

Beck, A.T., Steer, R.A. \& Brown, G.K. (1996). Manual for the Beck Depression Inventory (2nd edn). San Antonio, TX: The Psychological Corporation. 
Beck, A.T., Weissman, A.T., Lester, D. \& Trexler, L. (1974). The Measurement of pessimism: the hopelessness scale. Journal of Consulting and Clinical Psychology, 42(6), 861-865.

Birchwood, M., Smith, J., Drury, V. \& Healy, J. (1994). A self-report Insight Scale for psychosis: reliability, validity and sensitivity to change. Acta Psychiatrica Scandinavica, $89(1), 62$.

Cochran, S.D. (1984). Preventing medical non-compliance in the outpatient treatment of bipolar affective disorders. Journal of Consulting and Clinical Psychology, 52(5), 873878.

Colom, F., Vieta, E., Martinez-Aran, A., Reinares, M., Goikolea J.M., Benabarre, A., Torrent, C., Comes, M., Corbella, B., Parramon, G. \& Corominas, J. (2003). A randomized trial on the efficacy of group psychoeducation in the prophylaxis of recurrences in bipolar patients whose disease is in remission. Archives of General Psychiatry, 60, 402-407.

Coryell, W., Scheftner, W., Keller, M., Endicott, J., Maser, J., \& Klerman, G. L. (1993). The enduring psychosocial consequences of mania and depression. American Journal of Psychiatry, 150, 720-727.

Dalton, E. J., Cate-Carter, T. D., Mundo, E., Parikn, S. V., \& Kennedy, J. L. (2003). Suicide risk in bipolar patients: The role of co-morbid substance use disorders. Bipolar Disorders, 5, 58-61.

Das Gupta, R., \& Guest, J. F. (2002). Annual cost of bipolar disorder to UK society. British Journal of Psychiatry, 180, 227-233.

Dozois, D.J.A., Dobson, K.S. \& Ahnberg, J.L. (1998) A psychometric evaluation of the Beck Depression Inventory-II. Psychological Assessment, 10(2), 83-89.

Garfield, S.L. (1981). Evaluating the psychotherapies. Behaviour Therapy, 12, 292-307.

Gitlin, M.J., Swendsen, J., Heller, T. \& Hammen, C. (1995). Relapse and impairment in bipolar disorder. American Journal of Psychiatry, 152, 1635-1640.

Greene, S. (1981). Levels of measured hopelessness in the genral population. British Journal of Clinical Psychology, 20, 11-14.

Greenhouse, W.J., Meyer, B. \& Johnson, S.L. (2000). Coping and medictaion adherence in bipolar disorder. Journal of Affective disorders, 59, 237-241.

Hughdahl, K. \& Ost, L. (1981). On the difference between statistical and clinical significance. Behaviour Assessment, 3, 289-295. 
Jacobson, N.S., Follette, W.C. \& Revenstorf, D. (1984). Psychotherapy outcome research: methods for reporting variability and evaluating clinical significance. Behaviour Therapy, $15,336-352$.

Jacobson, N.S., Follette, W.C. \& Revenstorf D. (1986). Toward a standard definition of clinically significant change. Behaviour Therapy, 17, 308-311.

Jacobson, N.S. \& Revenstorf, D. (1988). Statistics for assessing the clinical significance of psychotherapy techniques: issues, problems and new developments. Behaviour Assessment, 10, 133-145.

Jacobson, N.S., Roberts, L.J., Berns, S.B. \& McGlinchey, J.B. (1999). Methods for defining and determining the clinical significance of treatment effects in mental health research: Description, application and alternatives. Journal of Consulting and Clinical Psychology, 67, 300-307.

Jacobson, N. S. \& Truax, P. (1991). Clinical significance: A statistical approach to defining meaningful change in psychotherapy research. Journal of Consulting and Clinical Psychology, 59, 12-19.

Kazdin, A.E. (1982). Single case research designs: methods for clinical and applied settings. NY: Oxford University Press.

Kazdin, A.E. \& Wilson, G.T. (1978a). Criteria for evaluating psychotherapy. Archives of General Psychiatry, 35, 407- 416.

Keck, P.E., McElroy, S.L., Strakowski, S.M., Bourne, M.L. \& West, S.A. (1997).

Compliance with maintenance treatment in bipolar disorder. Psychopharmacological Bulletin, 33(1), 87-91.

Kendall, P.C. (1984). Behavioral assessment and methodology. In G.T. Wilson, C.M. Granks, K.D. Brownell, \& P.C. Kendall (Eds). Annual review of behavior therapy (Vol. 9, pp. 47-86). New York: Guilford Press.

Lam, D.H., Bright, J., Jones, S., Hayward, P., Schuck, N., Chisholm, D. \& Sham, P. (2000). Cognitive therapy for bipolar illness. A pilot study of relapse prevention. Cognitive Therapy and Research, 24(5), 503-520.

Lam, D.H., Hayward, P., Watkins, E.R., Wright, K. \& Sham, P. (2005). Relapse prevention in patients with bipolar disorder. The American Journal of Psychiatry, 162(2), 324-329. 
Lam, D.H., Jones, S.H., Hayward, P. \& Bright J.A. (1999). Cognitive therapy for Bipolar Disorders. Chichester: Wiley.

Lam, D.H., Watkins, E.R., Hayward, P., Bright, J., Wright, K., Kerr, N., Parr-Davis, G. \& Sham, P. (2003). A Randomized controlled study of cognitive therapy for relapse prevention for bipolar affective disorder. Archives General Psychiatry, 60,145-152.

Larsen, D.L., Attkisson, C.C., Hargreaves, W.A. \& Nguyen, T.D. (1979). Assessment of client/patient satisfaction: development of a general scale. Evaluation and Program Planning, 2, 197-207.

McIntyre, R.S., Muzina, D.J., Kemp, D.E., Blank, D., Woldeyohannes, H.O., Lofchy, J., Soczynska, J.K., Banik, S. \& Kornaski, J.K. (2008). Bipolar Disorder and suicide: Research synthesis and clinical translation. Current Psychiatry Reports, 10(1), 32-46.

Michalak, E.E., Yatham, L. N. \& Lam, R. W. (2005). Quality of life in bipolar disorder: A review of the literature. Health and Quality of Life Outcomes, 7, 6.

Michalak, E.E., Yatham, L. N., Maxwell, V., Hale, S. \& Lam, R. W. (2007). The impact of bipolar disorder upon work functioning: A qualitative analysis. Bipolar Disorders, 9(1-2), 126-143.

Miklowitz, D. J. \& Johnson, S. L. (2006). The psychopathology and treatment of bipolar disorder. Annual Review of Clinical Psychology, 2, 199-235.

Miklowitz, D.J., Simoneau, T.L., George, E.L., Richards, J.A., Kalbag, A., Scachs-Ericsson, N. \& Suddath, R. (2000). Family-focused treatment of bipolar disorder: 1-year effects of a psychoeducational program in conjunction with pharmacotherapy. Society of Biological Psychiatry, 48, 582-592.

Newman, C. F. (2005). Reducing the risk of suicide in patients with bipolar disorder: Interventions and safeguards. Cognitive and Behavioral Practice, 12(1), 76-88.

Pallant, J.F. (2000). Development and validation of a scale to measure perceived control of internal states. Journal of Personality Assessment, 75(2), 308-337.

Perry, A., Tarrier, N., Morris, R., McCarthy, E. \& Limb, K. (1999). Randomised controlled trial of efficacy of teaching patients with bipolar disorder to identify early symptoms of relapse and obtain treatment. British Medical Journal, 318, 149-153.

Post, R.M., Kirk, D. D., Gabriele, S.L., Lori, L.A., Mark, A.F., Trisha, M.S., Rush, J.A., Keck, 
McElroy, S.L., Luckenbaugh, D.A., Polio, C., Kupka, R. \& Nolen, W.A. (2003). Morbidity in 258 bipolar outpatients followed for 1 year with daily prospective ratings on the NIMH life chart method. Journal of Clinical Psychiatry, 64(6), 680-689.

Regeer, E.J., Have, M., Rosso, M.L., Hakkaart-Van Roijen, L., Vollebergh, W. \& Nolen, W.A. (2004). Prevalence of bipolar disorder in the general population: A reappraisal study of the Netherlands mental health survey and incidence study. (NEMESIS). Acta Psychiatrica Scandinavica, 110(3), 374-382.

Scott, J., Garland, A. \& Morhead, S. (2001). A pilot study of cognitive therapy in bipolar disorders. Psychological Medicine, 31, 459-467.

Scott, J., Paykel, E., Morris, E., Bentall, R., Kinderman, P., Johnson, T., Abbott, R. \& Hayhurst, H. (2006) Cognitive-behavioural therapy for severe and recurrent bipolar disorders. British Journal of Psychiatry, 188, 313-320.

Simon, G. E., Ludman, E. J., Unutzer, J., Operskalski, B. H. \& Baver, M. S. (2008). Severity of mood symptoms and work productivity in people treated for bipolar disorder. Bipolar Disorders, 10(6), 718-725.

Sorensen J. (2005) Relapse prevention in bipolar disorder. A treatment manual and workbook for therapist and client. Hertfordshire: University of Hertfordshire Press.

Sorensen, J., Done, J. \& Rhodes, J. (2007). A case series evaluation of a brief, psychoeducation approach intended for the prevention of relapse in bipolar disorder. Behavioural and Cognitive Psychotherapy, 35, 93-107.

Wolf, M.M. (1978). Social validity: The case for subjective measurement or how applied behavior analysis is finding its heart. Journal of Applied Behaviour Analysis, 11, 203-214.

World Health Organisation (WHO) (1990). The International Statistical Classification of Diseases and Related Health Problems, $10^{\text {th }}$ Revision.

Zubin, J. \& Spring, B. (1977). Vulnerability: A new view of schizophrenia. Journal of Abnormal Psychology, 86(2), 103-26. 
About the authors:

Dr Maria Jose Gutierrez-Ros is a Consultant Clinical Psychologist and was appointed Head of Adult Community Psychology in South Essex NHS Trust in June 2005. As well as having responsibility for coordinating the provision of secondary psychological services across South Essex, she continues through her clinical practice to provide therapeutic interventions to clients with complex and severe mental health problems. Her special area of interest and research is in the treatment of people with Bipolar Disorder and has published previously in this area.

Address for correspondence: Dr Maria J. Gutierrez-Ros, South Essex NHS Trust, The Adult Community Psychology Service, Resource Community Centre, Basildon Mental Health Unit, Basildon Hospital, Nethermayne Basildon Essex SS16 5NL

E-mail: Maria-jose.gutierrez@sept.nhs.uk

Dr John Sorensen is a Consultant Clinical Psychologist in secondary care psychological services and has experience in the delivery of therapy to adults with a wide range of mental health problems. He routinely conducts research evaluations of his own treatment packages and has published in books and peer reviewed journals on topics ranging from 'relapse prevention in severe mental illness to 'emotional intelligence in NHS management'. He also teaches on a wide range of subjects to Doctor of Clinical Psychology students at three separate universities and regularly provides workshops to psychiatrists and mental health nurses in the UK and abroad'.

E-mail:Sj4cc@yahoo.co.uk

In 2006 Ms Tomlinson completed an undergraduate degree in Psychology with Physical and Mental Health (BSC Hons) at the University of Reading. She assisted on the research submitted whilst being employed as an Assistant Psychologist for South Essex NHS Foundation Trust. She is now working as an Assistant Psychologist in a specialist psychotherapy service for East London NHS Foundation Trust and has continued an interest in research through assisting on two studies; exploring narrative therapies for black minority ethnic groups and a 'what works for whom' outcome predictor study. She is also contributing to a personality disorder health economics audit.

E-mail: emilytomlinson@hotmail.co.uk 